in vivo $35: 69-73(2021)$

doi:10.21873/invivo.12233

Review

\title{
An Update on Clinicopathological, Imaging and Genetic Features of Desmoplastic Fibroblastoma (Collagenous Fibroma)
}

\author{
SHIZUHIDE NAKAYAMA ${ }^{1}$, JUN NISHIO ${ }^{1}$, MIKIKO AOKI ${ }^{2}$, \\ KAZUKI NABESHIMA ${ }^{2}$ and TAKUAKI YAMAMOTO ${ }^{1}$ \\ ${ }^{1}$ Department of Orthopaedic Surgery, Faculty of Medicine, Fukuoka University, Fukuoka, Japan; \\ ${ }^{2}$ Department of Pathology, Faculty of Medicine, Fukuoka University, Fukuoka, Japan
}

\begin{abstract}
Desmoplastic fibroblastoma (also known as collagenous fibroma) is an uncommon benign fibroblasticl myofibroblastic neoplasm that primarily arises in the subcutaneous tissue of upper extremity. Magnetic resonance imaging reveals a well-defined mass in intimate association with dense connective tissue and prominent low signal intensity on all pulse sequences. Peripheral and septal enhancement is usually seen after intravenous contrast. Histologically, the lesion is paucicellular and consists of spindle to stellate-shaped cells embedded in a collagenous or myxocollagenous stroma with low vascularity. Diffuse and strong nuclear immunoreactivity for FOS-like antigen 1 seems to be characteristic of desmoplastic fibroblastoma. Cytogenetic studies have demonstrated the presence of $11 q 12$ rearrangements and an identical $t(2 ; 11)(q 31 ; q 12)$ translocation. This review provides an updated overview of the clinical, radiological, histological, cytogenetic and molecular genetic features of desmoplastic fibroblastoma and discusses the relationship to fibroma of tendon sheath.
\end{abstract}

Desmoplastic fibroblastoma, also known as collagenous fibroma, is a rare benign soft-tissue tumor first described in 1995 by Evans (1). It belongs to the fibroblastic/ myofibroblastic tumor group according to the 2020 World

This article is freely accessible online.

Correspondence to: Jun Nishio, MD, Ph.D., Department of Orthopaedic Surgery, Faculty of Medicine, Fukuoka University, 745-1 Nanakuma, Jonan-ku, Fukuoka 814-0180, Japan. Tel: +81 928011011, Fax: +81 928649055, e-mail: jnishio@cis.fukuoka-u.ac.jp

Key Words: Desmoplastic fibroblastoma, collagenous fibroma, cytogenetics, magnetic resonance imaging, FOSL1, review.
Health Organization Classification of Soft Tissue Tumors (2). Desmoplastic fibroblastoma can show morphological overlap with fibroma of tendon sheath (see below). In our experience, it is sometimes difficult to distinguish between these two tumor types, especially when examining limited tissue specimens. This review highlights the clinical, radiological, histological, cytogenetic and molecular genetic features of desmoplastic fibroblastoma and discusses the relationship to fibroma of tendon sheath.

\section{Clinical Presentation}

Desmoplastic fibroblastoma has a peak incidence in the fifth to seventh decades of life, with a male predominance. Few cases have been encountered in children $(3,4)$. It typically presents as a firm, mobile, slow-growing, painless, subcutaneous mass, often of relatively long duration. Fascial and skeletal muscle involvement is relatively common. Desmoplastic fibroblastoma shows a wide anatomic distribution but occurs most frequently in the upper arm, shoulder and upper back. The diameter ranges from 1 to 20 $\mathrm{cm}$ (median of $3 \mathrm{~cm}$ ) (5). Simple excision is the treatment of choice and no local recurrence has been reported (2).

\section{Radiological Features}

The radiographic, ultrasonographic and computed tomographic (CT) features of desmoplastic fibroblastoma are not specific but magnetic resonance imaging (MRI) features are relatively characteristic. In our experience, the most significant differential diagnosis to be considered is desmoidtype fibromatosis, which may require more aggressive treatment. It is important to be familiar with the key imaging features of desmoplastic fibroblastoma for its accurate diagnosis and appropriate treatment. 

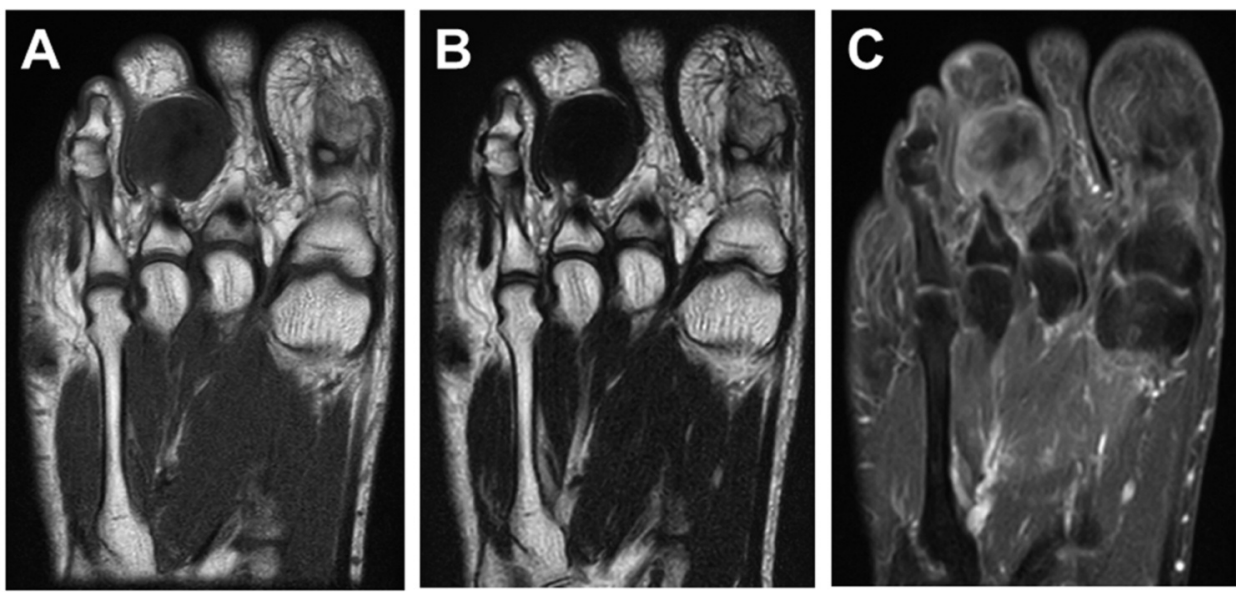

Figure 1. Coronal magnetic resonance images of desmoplastic fibroblastoma surrounding the flexor tendon of the third toe in a 46-year-old man. A: T1-weighted sequence showed a mildly heterogeneous mass with signal intensity similar to or less than that of skeletal muscle. B: T2-weighted sequence showed that the mass had low signal intensity. C: Contrast-enhanced fat-suppressed T1-weighted sequence revealed mild heterogeneous internal enhancement with peripheral enhancement.

Radiographs may be normal or show a soft tissue mass without calcification. Although cases of osseous erosion or invasion have been described (6-9), the underlying bone is typically normal. Limited experience with ultrasonography is that it reveals a heterogeneous mass with mixed echogenicity. Color Doppler examination may display no significant vascularity (9). CT demonstrates a homogeneous soft-tissue mass with tissue attenuation similar to that of skeletal muscle. On MRI, the lesion is well-defined and adjacent to dense connective tissue. Desmoplastic fibroblastoma usually exhibits variable amounts of low to intermediate signal intensity on T1-weighted images (Figure 1A) and inhomogeneously low to slightly high signal intensity on T2-weighted images (Figure 1B). On fluid-sensitive images, the lesion is more heterogeneous, generally showing a wider spectrum of reduced to intermediate signal intensity. Contrast-enhanced MRI demonstrates peripheral and septal enhancement with patchy areas of homogeneity (9) (Figure 1C). In contrast, desmoid-type fibromatosis exhibits more infiltrative growth and more uniform moderate-to-avid enhancement. A prominent low signal-intensity band on all pulse sequences can be seen in desmoid-type fibromatosis. We suggest that the enhancement pattern and the presence of a low signalintensity band may be useful to distinguish desmoplastic fibroblastoma and desmoid-type fibromatosis. To date, position-emission tomography features for desmoplastic fibroblastoma have been described in only two cases (9, 10). Integrated positron-emission tomography/CT images show mild focal fluorodeoxyglucose uptake by the lesion, with a maximum standardized uptake value of 2.4 and 3.5, respectively.
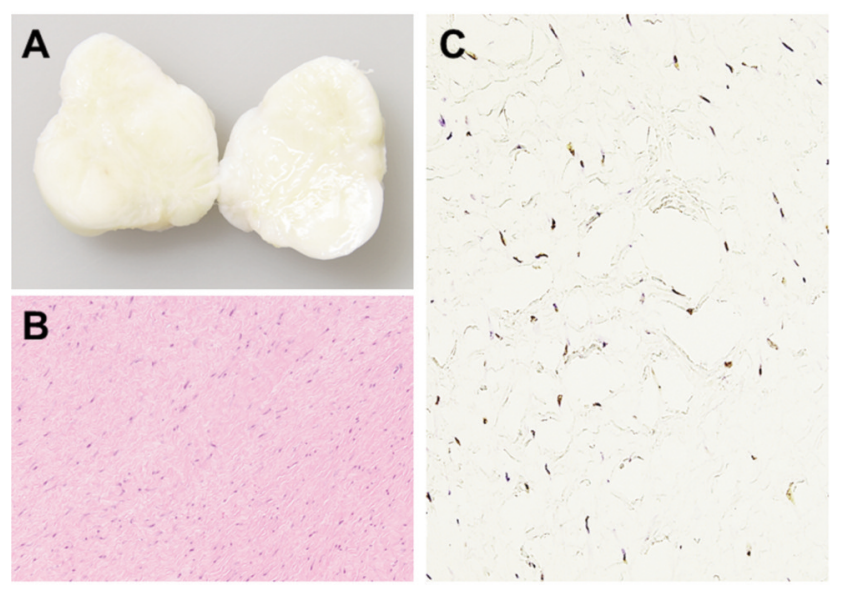

Figure 2. Histological and immunohistochemical features of desmoplastic fibroblastoma. A: Gross appearance showing a wellcircumscribed mass with a pearl-gray cut surface. B: The tumor was hypocellular and consisted of spindled and stellate-shaped cells in a dense collagenous stroma (hematoxylin and eosin staining, original magnification $\times 100)$. C: The tumor cells showed nuclear immunoreactivity for FOS-like antigen 1 (original magnification ×200).

\section{Histological and Immunohistochemical Characteristics}

Grossly, desmoplastic fibroblastoma appears as a wellcircumscribed mass with a white to pearl-gray cut surface (Figure 2A). Histologically, the lesion is hypocellular and consists of spindle to stellate-shaped cells embedded in an abundant collagenous or myxocollagenous stroma (Figure 2B). 
Table I. Chromosomal changes in desmoplastic fibroblastoma.

\begin{tabular}{|c|c|c|c|c|}
\hline Case & Age, years/gender & Location & Karyotype & Reference \\
\hline 1 & $63 / \mathrm{M}$ & Hand & $\begin{array}{l}45, \mathrm{X}, \mathrm{t}(\mathrm{Y} ; 7)(\mathrm{q} 12 ; \mathrm{q} 35), \mathrm{t}(1 ; 6)(\mathrm{q} 34 ; \mathrm{q} 15),-3, \operatorname{der}(5) \operatorname{inv}(5)(\mathrm{p} 13 \mathrm{q} 11) \operatorname{add}(5) \\
(\mathrm{q} 32), \mathrm{t}(8 ; 22)(\mathrm{q} 11 ; \mathrm{p} 11), \mathrm{t}(11 ; 20)(\mathrm{q} 12 ; \mathrm{q} 13), \operatorname{add}(15)(\mathrm{q} 24), \operatorname{add}(17)(\mathrm{q} 24)\end{array}$ & Sciot et al. (12) \\
\hline 2 & $37 / \mathrm{M}$ & Thigh & $46, \mathrm{XY}, \mathrm{t}(2 ; 11)(\mathrm{q} 31 ; \mathrm{q} 12), \mathrm{t}(9 ; 15)(\mathrm{q} 34 ; \mathrm{q} 14)$ & Sciot et al. (12) \\
\hline 3 & $55 / \mathrm{M}$ & Supraclavicular & $46, \mathrm{XY}, \mathrm{t}(1 ; 3)(\mathrm{p} 31 ; \mathrm{q} 21), \mathrm{t}(2 ; 11)(\mathrm{q} 31 ; \mathrm{q} 12)$ & Bernal et al. (13) \\
\hline $\begin{array}{l}4 \\
(14)\end{array}$ & $44 / \mathrm{F}$ & Knee & 46,XX,add(11)(q12),add(12)(q2) & Sakamoto et al. \\
\hline 5 & $54 / \mathrm{F}$ & Knee & $46, \mathrm{XX}, \mathrm{t}(11 ; 17)(\mathrm{q} 12 ; \mathrm{p} 11.2)$ & Maghari et al. (15) \\
\hline 6 & $58 / \mathrm{F}$ & Thigh & $46, \mathrm{XX}, \mathrm{t}(10 ; 11)(\mathrm{p} 15 ; \mathrm{q} 12)$ & Macchia et al. (16) \\
\hline 7 & $61 / \mathrm{M}$ & Thigh & $46, \mathrm{XY}, \mathrm{t}(2 ; 4 ; 11)(\mathrm{q} 34 ; \mathrm{q} 32 ; \mathrm{q} 12)$ & Macchia et al. (16) \\
\hline 8 & $20 / \mathrm{F}$ & Preauricular & $46, \mathrm{XX}, \operatorname{der}(5) \operatorname{del}(5)(\mathrm{q} 12 \mathrm{q} 14) \operatorname{ins}(5 ; ?)(\mathrm{q} 32 ; ?), \operatorname{ins}(12 ; ?)(\mathrm{q} 22 ; ?)$ & Macchia et al. (16) \\
\hline 9 & $77 / \mathrm{M}$ & Hand & $46, \mathrm{XY}, \mathrm{t}(5 ; 11)(\mathrm{q} 21 ; \mathrm{q} 12)$ & Macchia et al. (16) \\
\hline 10 & $57 / \mathrm{M}$ & Thigh & $46, \mathrm{XY}, \mathrm{t}(2 ; 11)(\mathrm{q} 35 ; \mathrm{q} 13) / 46$, idem,t( $5 ; 14)(\mathrm{q} 15 ; \mathrm{q} 22)$ & Nishio et al. (17) \\
\hline 11 & $63 / \mathrm{F}$ & Shoulder & $47, \mathrm{XX},+8$ & Nishio et al. (18) \\
\hline
\end{tabular}

F: Female; M: male.
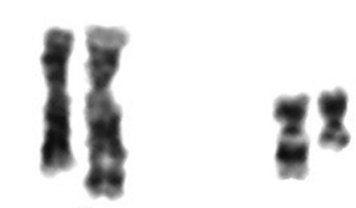

Chromosome 2 Chromosome 11

Figure 3. Partial giemsa-trypsin-giemsa (GTG)-banded karyotype showing a characteristic 2;11 translocation in desmoplastic fibroblastoma.

Slit-like blood vessels are generally scarce and inconspicuous. Mitotic figures are uncommon and necrosis is absent. Immunohistochemically, the tumor cells are positive diffusely for vimentin and focally for smooth muscle actin. Occasional cases may exhibit scattered cells that stain for keratin (5). Immunostains for desmin, S-100 protein, CD34, epithelial membrane antigen and $\beta$-catenin are typically negative. Notably, diffuse and strong nuclear immunoreactivity for FOSlike antigen 1 (FOSL1) is seen in desmoplastic fibroblastoma (Figure 2C), in contrast to the absence of overexpression in other histological mimics including fibroma of tendon sheath and desmoid-type fibromatosis (11). Therefore, FOSL1 staining is an extremely useful adjunct in the diagnosis of desmoplastic fibroblastoma, particularly in small specimens.

\section{Cytogenetic and Molecular Genetic Features}

Only 11 cases of desmoplastic fibroblastoma have been cytogenetically characterized in the literature (12-18) (Table I). Desmoplastic fibroblastoma displays mostly simple karyotypes characterized by one or few chromosomal rearrangements or numerical aberrations. The long arm of chromosome 11, in particular 11q12, was involved in almost all cases. Moreover, we reported a case of desmoplastic fibroblastoma with trisomy

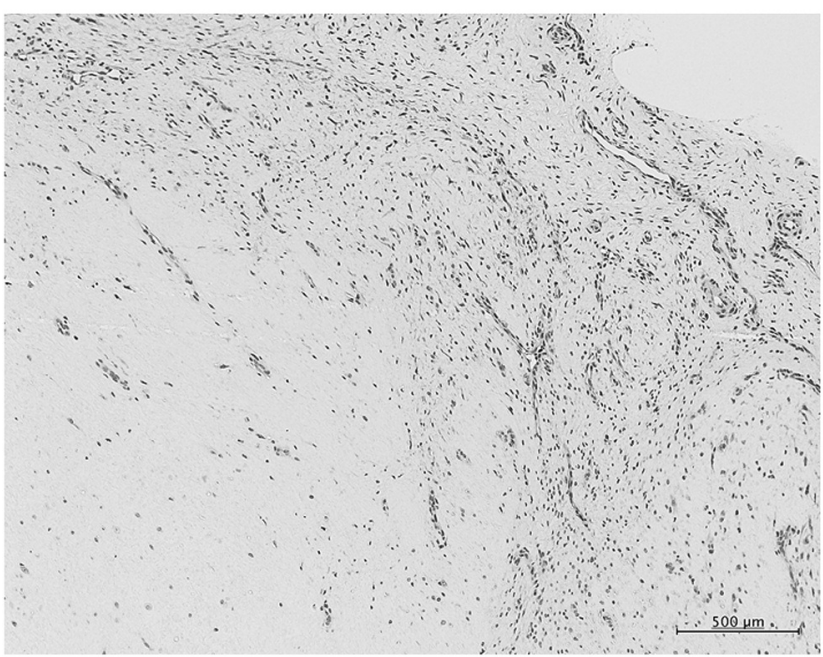

Figure 4. Histological features of fibroma of tendon sheath. The tumor consisted of bland spindle cells in a dense collagenous stroma. Slit-like thin-walled vessels can be seen (hematoxylin and eosin staining, original magnification $\times 100$ ).

8 as the sole cytogenetic anomaly (18). Notably, an identical $\mathrm{t}(2 ; 11)(\mathrm{q} 31 ; \mathrm{q} 12)$ translocation was detected in two cases (12, 13). We also observed the presence of a 2;11 translocation with slightly distal breakpoints (2q35 and 11q13) (17) (Figure 3). These cytogenetic studies strongly suggest that $11 \mathrm{q} 12$ rearrangement is characteristic of desmoplastic fibroblastoma. It is of interest that the same translocation was identified in a case of fibroma of tendon sheath (19), suggesting a pathogenetic link between these two entities.

Recently, global gene expression profile and quantitative real-time polymerase chain reaction have shown that the functional outcome of 11q12 rearrangement is deregulation 
Table II. Chromosomal changes in fibroma of tendon sheath.

\begin{tabular}{|c|c|c|c|c|}
\hline Case & Age, years/gender & Location & Karyotype & Reference \\
\hline 1 & $60 / \mathrm{F}$ & Finger & $46, \mathrm{XY}, \mathrm{t}(2 ; 11)(\mathrm{q} 31-32 ; \mathrm{q} 12)$ & Dal Cin et al. (19) \\
\hline 2 & $38 / \mathrm{F}$ & Hand & $\begin{array}{c}46, \mathrm{XX}, \mathrm{t}(9 ; 11)(\mathrm{p} 24 ; \mathrm{q} 13-14) / 46, \mathrm{XX}, \mathrm{t}(1 ; 20)(\mathrm{p} 13 ; \mathrm{q} 13.1) / 46, \mathrm{XX}, \mathrm{t}(1 ; 2) \\
(\mathrm{q} 21 ; \mathrm{q} 35) / 46, \mathrm{XX}, \mathrm{t}(3 ; 16)(\mathrm{p} 21 ; \mathrm{q} 24)\end{array}$ & Nishio et al. (23) \\
\hline 3 & $63 / \mathrm{M}$ & Knee & $\begin{array}{c}46, \mathrm{XY}, \operatorname{del}(9)(\mathrm{q} ?), \operatorname{der}(16) \operatorname{add}(16)(\mathrm{p} 11.2) \operatorname{add}(16)(\mathrm{q} 24) / 46, \mathrm{XY}, \mathrm{t}(11 ; 15) \\
(\mathrm{q} 23 ; \mathrm{q} 22) / 46, \mathrm{XY}, ? \mathrm{t}(5 ; 14)(\mathrm{q} 35 ; \mathrm{q} 11.2)\end{array}$ & Suzuki et al. (24) \\
\hline 4 & $14 / \mathrm{M}$ & Hand & $46, X Y, t(4 ; 10)(\mathrm{p} 16 ; \mathrm{q} 24), \operatorname{add}(10)(\mathrm{q} 22)$ & Rubinstein et al. (25) \\
\hline
\end{tabular}

F: Female; M: male.

of FOSL1 expression in desmoplastic fibroblastoma (16). On the other hand, chromogenic in situ hybridization analysis revealed no rearrangement of the FOSL1 gene locus in any cases of desmoplastic fibroblastoma examined (11). Further studies are required to elucidate the mechanism of FOSL1 overexpression in desmoplastic fibroblastoma.

\section{Fibroma of Tendon Sheath}

Fibroma of tendon sheath is a benign fibroblastic/ myofibroblastic tumor that is usually attached to a tendon (sheath) (20). It has a peak incidence in the third to fifth decades of life, with a male predominance. Fibroma of tendon sheath typically presents as a firm, small (usually less than $3 \mathrm{~cm}$ ), slowgrowing, painless mass in the hand (especially the thumb, index finger and middle finger). Simple excision is the treatment of choice but local recurrence is seen in $5-10 \%$ of cases (20).

Radiographs are usually normal or may demonstrate a nonspecific soft-tissue mass. Bone involvement is extremely uncommon. On MRI, the lesion has low to intermediate signal intensity on both T1- and T2-weighted images. Areas of increased signal intensity may be seen in lesions with components of increased cellularity or myxoid change. Fibroma of tendon sheath shows a variable enhancement pattern, ranging from no enhancement to marked enhancement (21). If fibroma of tendon sheath has a hypointense signal on all pulse sequences, it may have imaging features that overlap with those of desmoplastic fibroblastoma.

Histologically, the lesion is well circumscribed and consists of bland spindle cells embedded in a dense collagenous stroma. Focal myxoid matrix may be present. There are characteristic slit-like thin-walled vessels or clefts (Figure 4). Cytological atypia is generally not seen and mitotic activity is low. A cellular variant of this tumor has also been described (22). Immunohistochemically, the tumor cells are positive diffusely for vimentin and focally for smooth muscle actin. Notably, nuclear expression of FOSL1 is absent in fibroma of tendon sheath (11).

Clonal chromosomal aberrations were detected by cytogenetic analysis in four cases of fibroma of tendon sheath (19, 23-25) (Table II). These cytogenetic studies suggest that 11q rearrangement may be characteristic of (classic) fibroma of tendon sheath. To date, no candidate target gene for this chromosomal rearrangement has been identified. On the other hand, Carter et al. recently reported that ubiquitin-specific protease 6 (USP6) (located on 17p13) rearrangements were found in approximately $67 \%$ of cellular fibroma of tendon sheath but not in classic fibroma of tendon sheath (26). Most recently, anchored multiplex polymerase chain reaction/nextgeneration sequencing revealed pyruvate kinase $\mathrm{M} 1 / 2$, regulator of chromosome condensation 1, asporin, collagen type I alpha 1 chain, collagen type III alpha 1 chain and non-muscle myosin heavy chain 9 as fusion partners for USP6 in cellular fibroma of tendon sheath (27).

\section{Conclusion}

Desmoplastic fibroblastoma is a distinctive benign fibroblastic/myofibroblastic tumor and its associated prognosis is excellent with no recurrence. Contrast-enhanced MRI is especially useful and reveals peripheral and septal enhancement with varying areas of homogeneity. The use of FOSL1 immunostaining is a valuable adjunct in the diagnosis of desmoplastic fibroblastoma. A t $(2 ; 11)(\mathrm{q} 31 ; \mathrm{q} 12)$ translocation is characteristic of desmoplastic fibroblastoma. The presence of this balanced translocation has also been reported in a classic fibroma of tendon sheath. The radiological, histological and cytogenetic overlap between desmoplastic fibroblastoma and classic fibroma of tendon sheath suggests that they are closely related entities. Over the past few years, some novel fusions involving the USP6 gene have been identified in a subset of cellular fibroma of tendon sheath. Further studies will delineate how these lesions should best be classified.

\section{Conflicts of Interest}

The Authors declare no conflicts of interest associated with this article.

\section{Authors' Contributions}

SN researched the literature and drafted the article. JN collected the data and was a major contributor to writing the article. MA and KN 
performed the histopathological evaluations. TY reviewed the article. All Authors read and approved the final article.

\section{Acknowledgements}

This study was supported in part by the Ogata Foundation.

\section{References}

1 Evans HL: Desmoplastic fibroblastoma: A report of seven cases. Am J Surg Pathol 19: 1077-1081, 1995. PMID: 7661281.

2 Miettinen M and Bridge JA: Desmoplastic fibroblastoma. In: World Health Organization Classification of Tumours: Soft Tissue and Bone Tumours. Lyon, IARC Press, pp. 69-70, 2020.

3 Magro G and Venti C: Childhood desmoplastic fibroblastoma (collagenous fibroma) with a 12-year follow-up. Pediatr Dev Pathol 2: 62-64, 1999. PMID: 9841708. DOI: 10.1007/s100249900091

4 Nishio J, Iwasaki H, Nishijima T and Kikuchi M: Collagenous fibroma (desmoplastic fibroblastoma) of the finger in a child. Pathol Int 52: 322-325, 2002. PMID: 12031090. DOI: 10.1046/j.1440-1827.2002.01351.x

5 Miettinen M and Fetsch JF: Collagenous fibroma (desmoplastic fibroblastoma): A clinicopathologic analysis of 63 cases of a distinctive soft tissue lesion with stellate-shaped fibroblasts. Hum Pathol 29: 676-682, 1998. PMID: 9670823. DOI: $10.1016 / \mathrm{s} 0046-8177(98) 90275-1$

6 Beggs I, Salter DS and Dorfman HD: Synovial desmoplastic fibroblastoma of hip joint with bone erosion. Skeletal Radiol 28: 402-406, 1999. PMID: 10478622. DOI: 10.1007/s002560050537

7 Osipov V and Carrera GF: Collagenous fibroma (desmoplastic fibroblastoma) with vertebral body erosion. Sarcoma 2009: 682687, 2009. PMID: 19503798. DOI: 10.1155/2009/682687

8 Matsunobu T, Maekawa A, Fukushima S, Jotatsu M, Makihara $\mathrm{K}$, Hisaoka M and Iwamoto Y: Desmoplastic fibroblastoma invading the humerus. Case Rep Orthop 2020: 9780263, 2020. PMID: 32547801. DOI: 10.1155/2020/9780263

9 Kresse ME, Kransdorf MJ, Fox MG, Flug JA, Long JR and Murphey MD: Desmoplastic fibroblastoma: An uncommon tumor with a relatively characteristic MRI appearance. Am J Roentgenol 215: 178-183, 2020. PMID: 32406775. DOI: 10.2214/AJR.19.22163

10 Murata H, Imai K, Nakagawa K and Nishigaki Y: Multimodal radiological imaging of collagenous fibroma arising from the subacromial region in a patient with osteosarcoma: A case report. Mol Clin Oncol 10: 366-370, 2019. PMID: 30847175. DOI: $10.3892 / \mathrm{mco} .2019 .1798$

11 Kato I, Yoshida A, Ikegami M, Okuma T, Tonooka A, Horiguchi S, Funata N, Kawai A, Goto T, Hishima T, Aoki I and Motoi T: FOSL1 immunohistochemistry clarifies the distinction between desmoplastic fibroblastoma and fibroma of tendon sheath. Histopathology 69: 1012-1020, 2016. PMID: 27442992. DOI: 10.1111/his. 13042

12 Sciot R, Samson I, Van Den Berghe H, Van Damme B and Dal Cin P: Collagenous fibroma (desmoplastic fibroblastoma): Genetic link with fibroma of tendon sheath? Mod Pathol 12: 565-568, 1999. PMID: 10392630.

13 Bernal K, Nelson M, Neff JR, Nielsen SM and Bridge JA: Translocation $(2 ; 11)(\mathrm{q} 31 ; \mathrm{q} 12)$ is recurrent in collagenous fibroma (desmoplastic fibroblastoma). Cancer Genet Cytogenet 149: 161-163, 2004. PMID: 15036892. DOI: 10.1016/S0165-4608(03)00298-X
14 Sakamoto A, Yamamoto H, Yoshida T, Tanaka K, Matsuda S, Oda Y, Tsuneyoshi $\mathrm{M}$ and Iwamoto $\mathrm{Y}$ : Desmoplastic fibroblastoma (collagenous fibroma) with a specific breakpoint of 11q12. Histopathology 51: 859-860, 2007. PMID: 17894801. DOI: $10.1111 / \mathrm{j} .1365-2559.2007 .02861 . \mathrm{x}$

15 Maghari A, Ma N, Aisner S, Benevenia J and Hameed M: Collagenous fibroma (desmoplastic fibroblastoma) with a new translocation involving 11q12: A case report. Cancer Genet Cytogenet 192: 73-75, 2009. PMID: 19596257. DOI: 10.1016/ j.cancergencyto.2009.03.012

16 Macchia G, Trombetta D, Möller E, Mertens F, Storlazzi CT, Debiec-Rychter M, Sciot R and Nord KH: FOSL1 as a candidate target gene for $11 \mathrm{q} 12$ rearrangements in desmoplastic fibroblastoma. Lab Invest 92: 735-743, 2012. PMID: 22411068. DOI: $10.1038 /$ labinvest.2012.46

17 Nishio J, Akiho S, Iwasaki H and Naito M: Translocation $\mathrm{t}(2 ; 11)$ is characteristic of collagenous fibroma (desmoplastic fibroblastoma). Cancer Genet 204: 569-571, 2011. PMID: 22137488. DOI: 10.1016/j.cancergen.2011.10.003

18 Nishio J, Iwasaki H, Yano S and Naito M: Collagenous fibroma (desmoplastic fibroblastoma) with trisomy 8 as the sole cytogenetic abnormality. Anticancer Res 33: 3259-3262, 2013. PMID: 23898088.

19 Dal Cin P, Sciot R, De Smet L and Van den Berghe H: Translocation 2;11 in a fibroma of tendon sheath. Histopathology 32: 433-435, 1998. PMID: 9639118. DOI: 10.1046/j.1365-2559.1998.00390.x

20 Sciot R and Cunha IW: Fibroma of tendon sheath. In: World Health Organization Classification of Tumours: Soft Tissue and Bone Tumours. Lyon, IARC Press, pp. 67-68, 2020.

21 Fox MG, Kransdorf MJ, Bancroft LW, Peterson JJ and Flemming DJ: MR imaging of fibroma of the tendon sheath. Am J Roentgenol 180: 1449-1453, 2003. PMID: 12704067. DOI: 10.2214/ajr.180.5.1801449

22 Chung EB and Enzinger FM: Fibroma of tendon sheath. Cancer 44: 1945-1954, 1979. PMID: 91424. DOI: 10.1002/10970142(197911)44:5<1945::aid-cncr2820440558>3.0.co;2-t

23 Nishio J, Iwasaki H, Nagatomo M and Naito M: Fibroma of tendon sheath with $11 \mathrm{q}$ rearrangements. Anticancer Res 34: 5159-5162, 2014. PMID: 25202108.

24 Suzuki K, Yasuda T, Suzawa S, Watanabe K, Kanamori M and Kimura T: Fibroma of tendon sheath around large joints: Clinical characteristics and literature review. BMC Musculoskelet Disord 18: 376, 2017. PMID: 28854920. DOI: 10.1186/s12891-017-1736-5.

25 Rubinstein A, Fitzhugh V, Ahmed I and Vosbikian M: A case of 14-year-old male with fibroma of tendon sheath of the hand with novel chromosomal translocation 4;10. Case Rep Orthop 2019: 3514013, 2019. PMID: 31637074. DOI: 10.1155/2019/3514013.

26 Carter JM, Wang X, Dong J, Westendorf J, Chou MM and Oliveira AM: USP6 genetic rearrangements in cellular fibroma of tendon sheath. Mod Pathol 29: 865-869, 2016. PMID: 27125357. DOI: $10.1038 /$ modpathol.2016.83.

27 Mantilla JG, Gross JM, Liu YJ, Hoch BL and Ricciotti RW: Characterization of novel USP6 gene rearrangements in a subset of so-called cellular fibroma of tendon sheath. Mod Pathol, 2020. PMID: 32661296. DOI: 10.1038/s41379-020-0621-1

Received October 26, 2020

Revised November 5, 2020

Accepted November 10, 2020 